\title{
An Analysis of the Factors Influencing Journey Time Variation in the Cork Public Bike System
}

\author{
Cameron McBain and Brian Caulfield
}

\section{Abstract}

2 The Cork Public Bike System was opened in December 2014. This system consists of a total of 330 bikes 3 across 31 stations in Cork, with the scheme serving all the main trip attractors in the city. By using datasets 4 of all trips taken in the scheme during 2015 and 2016, a number of new spatial and temporal variables were assigned to all 560,000 trips that have been used for the analysis in this research, in addition to a journey 6 time that has been predicted by Google Maps for each individual route combination. These journey times from Google Maps were then compared with the actual journey times recorded in the dataset to create a new variable called Extra Travel Time.

10 Trips to and from stations that had a lower number of shops within walking distance were also found to be 11 likely predictors of the trips with lowest extra travel time. The stations with above average public transport 12 links also are associated with quicker trips suggesting that users of public bikes will take quick, direct 13 journeys if they are trip-chaining with other transportation modes such as bus or rail.

\section{Introduction and context}

Cork is a small city in the South-West of Ireland and is the second largest city in Ireland in terms of population with approximately 125,657 people living in the city (CSO, 2017). Cork currently has no light rail system in place and is only served by one heavy rail station, Cork Kent which is located on the NorthEast corner of the city with both commuter services to Mallow, Midleton and Cobh and InterCity services to Dublin and Tralee in operation. There are also a number of local bus services and there is also a bus station on the quays in the city centre. The introduction of the bike scheme in Cork is seen as a policy 23 intervention to increase cycling in the city in order for Cork to have a broader range of transportation 24 services, as both the Smart Travel (Department of Transport, 2009a) and National Cycling Policy 25 Framework (Department of Transport, 2009b) have outlined the introduction of public bike systems to 26 Irish urban areas as key future transport developments in Ireland. The two of these documents have set a 
1 target of $10 \%$ of nationwide trips to be by bicycle by 2020 , and the public bike system in Cork (along with

2 the other systems in Galway and Limerick) has been implemented to assist in reaching these bold targets.

4 As it has been two years since the scheme opened, there has been some research into different aspects of 5 how the scheme has been performed. Caulfield et al (2017) examined the usage patterns in a smaller sized 6 city (Cork), in order to see if smaller cities can derive benefits from public bike systems and provide a 7 prominent role in these cities. The research discovered that in Cork habitual trip patterns are found among regular uses and average trip times are mostly short in duration. It was also established that longer trips 9 were more likely to take place in better conditions along with other insights into the dynamics of a smaller 10 than usual public bike system. This paper used data from the first calendar year (2015) of operation while 11 the research conducted in this paper has continued building upon the knowledge of the Cork system with 12 the supplementation of the 2016 data. The primary research objectives were then defined and are as 13 follows:

14 - How much influence spatial and temporal variables have on the variation in journey times of all the different route combinations;

- How the journey times of different trips compare with the journey times predicted by Google Maps; and

- How the number of trips in the scheme varies with time

These research objectives were established to contribute to the existing literature of public bike systems and to assist policy makers and system operators in their planning processes of public bike system design and improvement, and could possibly argue the case for GPS tracking in the next generation of systems.

Other studies have shown that by using GPS tracking in a bike sharing scheme can result in more in-depth analysis and rich data on how these schemes are used (Wergin and Buehler, 2017; Broach et al, 2012; Hood et al, 2011). The cost involved in fitting bikes with GPS and the data protection issues concerned with this tracking may render wide scale tracking unfeasible. The approach presented in this paper tries to bridge the gap between rental times and travel times by comparing these using Google Maps travel times. The findings are a first step and further research in other cities would be interesting to compare against the findings from Cork. This is important because no information exists in this scheme, or in several others world wide, that measures the route taken by the cyclist. Comparing the recorded travel time with that of the anticipated travel time from Google Maps provides an indication the speed differences in the trips and that some cyclists may have taken more indirect and perhaps safer routes across the city. 


\section{Bike Sharing in Cork}

3 Cycling in Ireland, like many other countries, has seen increases over the past decade. The numbers cycling 4 in the major cities in Ireland (Dublin, Cork and Galway) are all on the increase (Caulfield, 2014). This 5 increase can be attributed to a number of factors. In 2009, a number of policies were introduced in Ireland 6 to encourage this growth in cycling. A tax-free loan bicycle purchase scheme called "Cycle to Work 7 Scheme". This was introduced to enable the public to purchase bikes with an up to $50 \%$ discount and some 8 research has shown this scheme to have been one of the main factors behind the increase in cycling in 9 Ireland (Caulfield and Leahy, 2011). Also in 2009, the first bike sharing scheme in Ireland opened in 10 Dublin. The success of the scheme in Dublin resulted in the opening of the Cork Bikes Scheme. The Public 11 Bike System was officially opened in Cork in December 2014 after the success of the Dublinbikes scheme 12 which launched in 2009. The Cork system consists of a total of 330 bikes across 31 stations in Cork city, 13 with the scheme serving all the main trip attractors in the city centre and University College Cork (National 14 Transport Authority, 2017). Caulfield et al (2017) completed the first study on the Cork Bikes scheme 15 showing that the majority of in the scheme were less than 6 minutes and frequent users had the lowest 16 travel times. Figure 1 details a map of the Cork Bikes scheme - section 5 provides more detail on the 17 locations and turnovers of these bike stations.

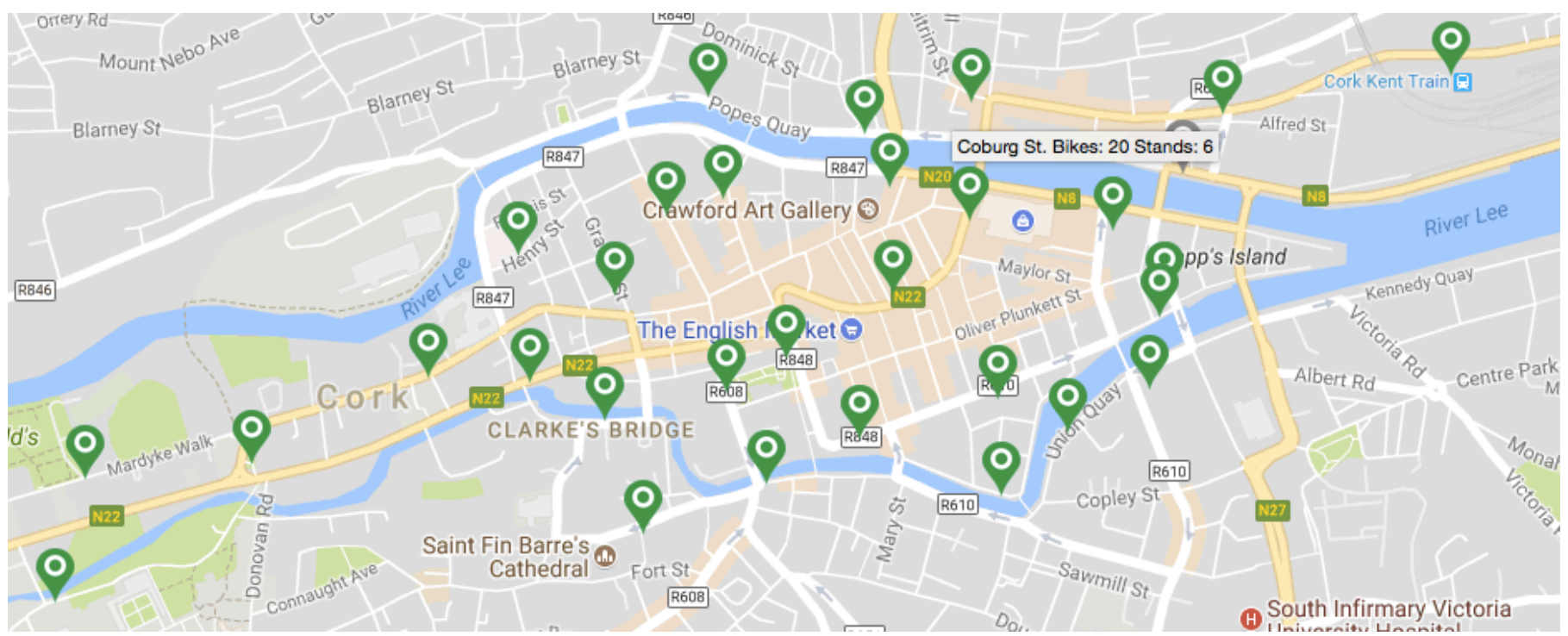

Figure 1 Cork Bikes Locations

\section{Literature Review}

23 Public bike systems around the world have attracted plenty of attention in the literature over the last number of years, as they are a sustainable mode of public transportation which can easily be integrated in 
1 the existing transportation network in their respective cities. After deciding to conduct this research on the

2 Cork public bike system, the first objective was to do a comprehensive search for all the literature on public

3 bike systems. The terms "public bikes" and "bike sharing" were searched and a total of 63 journal articles

4 from recent years were downloaded and reviewed. These relevant journal articles were categorised into:

5 Public Bike System Design; Public Bike System Maintenance; Public Bike Usage; User Surveys; and

6 Impacts of Public Bike Systems. As the topic of this research falls under Public Bike Usage, the literature

7 review in this article will primarily focus on this category. The existing articles that are grouped into the

8 category of Public Bike Usage can also be subcategorised into User Demographics, Typology of Users,

9 Usage and Stations, Travel Patterns and External Factor Influences.

\subsection{Travel Patterns}

12 Travel patterns in public bike systems tend to vary in both time and space and are usually related as spatio13 temporal patterns. Corcoran et al (2014) analysed the impact weather and calendar events have on these 14 spatio-temporal patterns in public bike usage by analysing data from the Brisbane CityCycle system. The 15 weather variables that were analysed were temperature, rainfall and wind speed and the calendar events that 16 were analysed were weekends, public holidays and school holidays, and these variables were used to create 17 a model that can predict travel patterns within the system. Faghih-Imani \& Eluru (2016) have also analysed 18 the New York CitiBike system in order to examine the impacts of spatio-temporal interactions.

O'Brien et al (2014) used data mining techniques on a wide range of public bike systems around the world. They have used the data to create a large database of each of the systems that analyses the variation in usage and infers the likely demographics which can be used to classify each system based on the spatial variations. They propose a wide range of applications which can be used from their new data source that includes rebalancing approaches, identifying areas for new bike stations or cycle lanes and better targeting for new members. Demand estimation can also be determined from data mining which is demonstrated by (Médard de Chardon \& Caruso, 2015). Oliveira et al (2016) in their methodology used a historical dataset of the New York CitiBike system to visually analyse the spatio-temporal travel patterns of the system. By mapping a pixel-orientated timeline the authors identified several patterns in the spatial and temporal domain, which could then also be applied to other systems in other cities. These visualisations can aid in analysing the travel patterns in large public bike systems, specifically for public bike system administrators,

31 rebalancing researchers and big data analysts. 


\subsection{External Factor Influences}

2 The usage of public bike systems can be influenced by external factors such as the cycling infrastructure

3 network, the built environment, land use and the variation in demand. There have been numerous papers written on these external factors which will be discussed in this sub-section. Fuller et al (2012) assessed the impact of a public transportation strike on public bike usage. The authors analysed public bike data from London on two separate days where there was a strike on the London Underground system and compared it with data from days of regular service. On the first day of the strike there was approximately a $30 \%$ increase in trips while on the second day there was almost a $100 \%$ increase. These results show that by 9 limiting transportation options, people will shift to public bike usage.

Faghih-Imani and Eluru (2014) examined numerous external factors that could affect public bike usage which included cycling infrastructure, meteorological conditions, built environment, land use and temporal characteristics. By analysing the usage data from the Montreal BIXI system they were able to develop a model that assesses the influence that each of these factors has, which can then be used for modifying other systems in order to maximise their usage. Several studies have also developed similar models which assess these conditions which also contribute to the knowledge of how external factors influence public bike usage

Zhao et al (2014) aimed to examine what influences the effectiveness of public bike systems in Chinese cities by considering the data of 69 different public bike systems. Ridership in these systems and turnover rate seemed to be influenced by external factors such as population density, government expenditure and the number of bike stations. Interestingly, they also found that the adoption of integrated travel cards that could be used for public bikes in addition to other transportation systems can significantly increase public bike usage due to ease of use, and should be considered for future schemes by policy makers.

As discussed, Faghih-Imani and Eluru (2014) examined the external factors influencing public bike usage. The authors furthered there research (Faghih-Imani and Eluru, 2016) in order to see how public bike system infrastructure, i.e. the number of bike stations and their capacities, can influence usage (using the Montreal BIXI system as the case study). They have taken a different approach within their research for this journal article as they postulate that previously developed models over-estimate the influence of infrastructure on ridership as the installation process is rarely considered. Their new model accounts for this bias and takes installation into account, and the results from this model support their hypothesis which demonstrates that installation of the infrastructure should also be taken into account of future models for system design. 


\subsection{How this Research will Complement the Existing Literature}

3 After reviewing each of the journal articles, it has been discovered that there has been little focus on the variation of journey times in public bike systems, which is why this research project has been undertaken. Some of the articles in this review on public bikes thus far have focussed on historical data which has also been investigated by Romanillos et al, (2016) in their review of big data and cycling but as far as this literature review reaches, there has been no investigation into how journey times vary due to different factors. This research will therefore contribute to the sub-topic of Public Bike Usage, by examining the different spatial and temporal factors that may be influencing variation in journey times across the Cork system.

\section{Methodology}

\subsection{Data Collection by the National Transport Authority}

15 The original datasets that are used in this research have been provided by the National Transport Authority 16 (NTA) of Ireland. The datasets were provided in two separate files, one set for 2015, which contained approximately 290,000 trip records, and the other for 2016, which contained approximately 309,000 trips. The data represents 731 days of operation (note 2016 was a leap year). Each of these datasets contained numerous variables for every single trip recorded within the Cork system in its first two full calendar years of operation such as the origin and destination stations, the time and date of when the bikes were taken out and returned, the distance between stations, whether the customer is an annual subscriber or using a temporary pass, a unique customer ID number and a bike ID number. The data provided for this research was anonymised so therefore no personal information on the name, age, gender, etc. of the users was provided in order to be in accordance with Irish data protection laws. The data also indicates if a refund was offered for the respective trip or if there was a fault such as the bike being returned immediately.

These two datasets were then merged together to create a master dataset which was then filtered prior to the creation of new variables and evaluation of the data. All temporary pass trips were filtered out as they were considered to be trips taken by visitors to the city and would not reflect the patterns of native users which is what has been examined in this research. Next the trips that were deemed to be faulty by the operator and trips which were refunded were also filtered out. This resulted in the removal of approximately 4,500 temporary pass trips and 35,000 faults or refunded trips. 
4.2 Calculation of Spatial and Temporal Variables

A significant number of new spatial and temporal variables were calculated and attributed to each trip, and are listed below (Table 6 has a breakdown of the descriptive statistics of the variables examined):

- Trip Duration: The time difference between when the bike was taken out from the origin station and when it is returned to the destination station.

- Month: The month of the year the trip took place.

- Season: Whether the trip took place in Winter (December - February), Spring (March - May), Summer (June - August) or Autumn (September - November).

- Day: The day of the week which the trip took place.

- Weekend: Whether the trip took place on either a weekday (Monday - Friday) or Weekend (Saturday - Sunday).

- Hour: The time the trip took place rounded to the closest hour.

- Time of Day: Whether the trip took place during the AM Peak (7am - 10am) or PM Peak (4pm $7 \mathrm{pm})$ travel period, Inter-peak (10am - 4pm) travel period or Off Peak (7pm - 7am) period.

- One-Way Street Start/End: Whether the street that the station is located on permits travel in one or two directions.

- Interior/Exterior Start/End: Stations deemed to be on the outer perimeter of the system were said to be exterior stations, while the remaining stations were said to be interior stations.

- Cycle Friendly Start/End: Whether the street that station is located on is deemed to be "Cycle Friendly" according to Google Maps.

- Shops Start/End: The number of shops within a 5 minute walk of the station.

- Restaurants Start/End: The number of restaurants within a 5 minute walk of the station.

- Public Transport Links Above or Below Average Start/End: Whether the station has above or below public transport links in terms of number of bus stops within a 5 minute walking distance

- Total Origin-Destination Pair Trips: The total number of trips that took place over the two-year period for that respective Origin-Destination pair.

- Total User Trips: The total number of trips that the user for that respective trip took over the twoyear period.

These new variables have been created primarily for the use of demonstrating the descriptive statistics of the system and for use as independent variables in both Stepwise Regression modelling and Multinomial Logistic (MNL) Regression modelling (discussed in later sub-sections). The authors did consider population and employment variables but the results they produced were not significant. 
3 As the primary goal of this research is to examine the factors that influence journey time variation in the

4 Cork system, the journey times obtained from the Google Maps journey planner perform an essential role

5 in creating the dependent variable used for the MNL Regression modelling. As there are 31 bike stations

6 located around Cork city this meant that there are a total of 961 different route combinations (in a $31 \times 31$

7 Origin-Destination matrix) that could be taken on a public bike at any given time. By entering the coordinates for the origin and destination stations for each of these 961 routes into the Google Maps

9 journey planner (Google Developers, 2016), an expected journey time is returned for driving, public 10 transport, cycling and walking. Every single cycling journey time was recorded for all of the routes which 11 were then attributed as a new variable to all of the trips in the dataset, based on their respective origin and 12 destination combination.

14 By then subtracting the expected Google Maps journey time from each actual observed trip duration, a new 15 variable called Extra Travel Time was created which essentially was the difference between the two 16 journey times, where a positive value indicated a trip that took longer than what Google Maps suggests and 17 a negative value represented a trip that was quicker than the suggested Google Maps journey time. These 18 values were segmented into quartiles based on how fast or slow these trips were compared to a predicted 19 journey time. Table 1 demonstrates the four quartiles of journey time variation, which were used as the 20 dependent variable for the principal MNL regression model. The results show that a large number of trips 21 are quicker as estimated by Google Map. The reasons for this are explored in the MNL regression model.

Table 1 Journey Time Variation

\begin{tabular}{|c|c|c|c|}
\hline \multicolumn{4}{|l|}{ Journey Time Variation } \\
\hline & Frequen & y|Perce & Cumulative Percent \\
\hline Valid|More than 46 seconds quicker & 139667 & 25.0 & 25.0 \\
\hline Between 46 seconds quicker and 35 seconds slower & 139470 & 24.9 & 49.9 \\
\hline Between 35 seconds and 2 minutes 26 seconds slowe & 140020 & 25.0 & 74.9 \\
\hline More than 2 minutes 26 seconds slower & 140296 & 25.1 & 100.0 \\
\hline Total & 559453 & 100.0 & \\
\hline
\end{tabular}

\subsection{Multinomial Logistic Regression Modelling}

The principal modelling approach that has been used to analyse the trip data and examine different trends is Multinomial Logistic Regression Modelling. MNL Regression is a type of modelling process which uses multiple equations to regress $\mathrm{k}$ categories of a dependent variable to multiple independent variables, estimating k - 1 logit equations (Statistics Solutions, 2017). SPSS compares each combination of k 
1 categories but just produces results for comparisons with either the first or last dependent variable category 2 by default.

4 The accuracy of the results produced is determined by the Nagelkerke $R^{2}$ value which is a pseudo $R^{2}$ 5 measure which is adjusted from the Cox and Snell $\mathrm{R}^{2}$ (IBM Knowledge Center, 2017). This pseudo $\mathrm{R}^{2}$ 6 value explains the proportion of variance of the dependent variable that is explained by the independent 7 variables, by comparing the log likelihood of the model to the log likelihood of a baseline model. The 8 interactions between the variables were tested for multicollinearity and the results found that none existed.

\section{5. Results \& Discussion}

115.1 Descriptive Statistics

$12 \quad 5.1 .1$ Station Turnover

13 The first set of results presented in this chapter are the descriptive statistics of the Cork system which 14 provide an overview of operation in its first two full calendar years of operation. Fig. 2 and Fig. 3 illustrate 15 how the bike stations in the system differ in terms of station turnover, i.e. which stations have the highest 16 frequency of trips as an origin station or a destination station. The busiest stations that trips tend to start and 17 end from are on the outskirts of the city, notably at Kent Station (rail station) and the three stations that 18 surround University College Cork (University Area), which are two major trip attractors in the city. The 19 stations also near St. Patrick's Street and the quays were found to be busy due to the high density of 20 restaurants and retail outlets in these areas. Some of the stations associated with less frequent usage are 21 generally located in areas in the city that have a lower population density or in close proximity to each 22 other, for example Clontarf Street and Lapp's Quay stations are only located 60m from each other. 

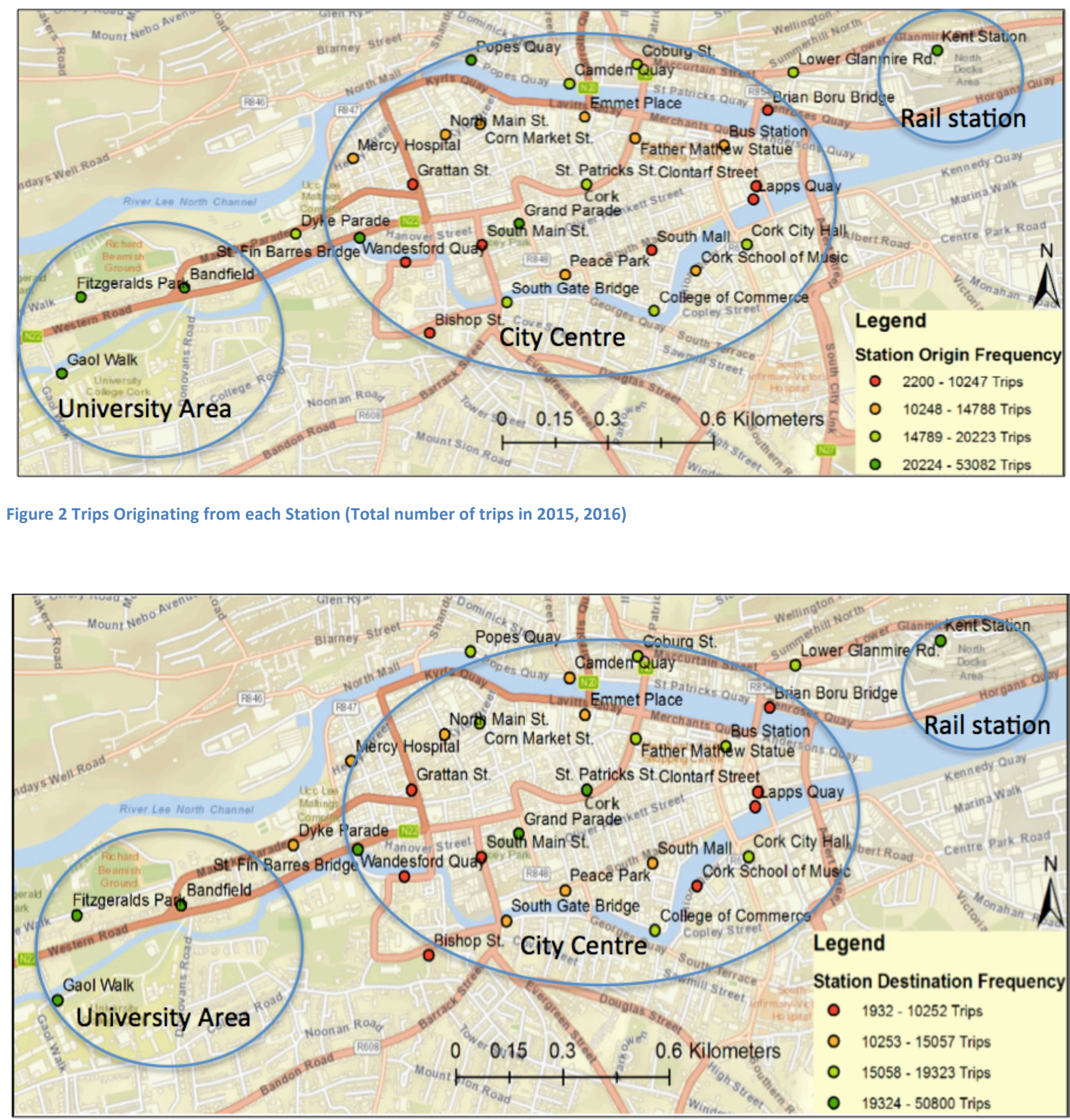

Figure 3 Trip Destinations per Station (Total number of trips in 2015, 2016)

\subsubsection{Trip Distribution by Duration \& Journey Time Variation}

8 Fig. 4 displays the distribution of trip durations that are made in the Cork system. The mean trip duration is

97.1 minutes with a standard deviation of 4.5 minutes, and follows a relatively normal shape with a slight

10 tail for extremely long trips. Less than $3 \%$ of the trips in the dataset had a trip duration of over 30 minutes

11 which is the threshold for which the user begins to be charged for their rental time. These trips are not 
1 included in Fig. 4 in order to enhance the graphical display of the distribution. Fig. 5 then shows the 2 distribution of the Extra Travel Time Variable which essentially demonstrates the distribution of the 3 "quickness" of each trip, as the duration of each individual trip is compared against the expected journey 4 time for that route on Google Maps journey planner. The mean of this distribution of this variable is 1.3 5 minutes longer than Google Maps with a standard deviation of 4.1 minutes.

6

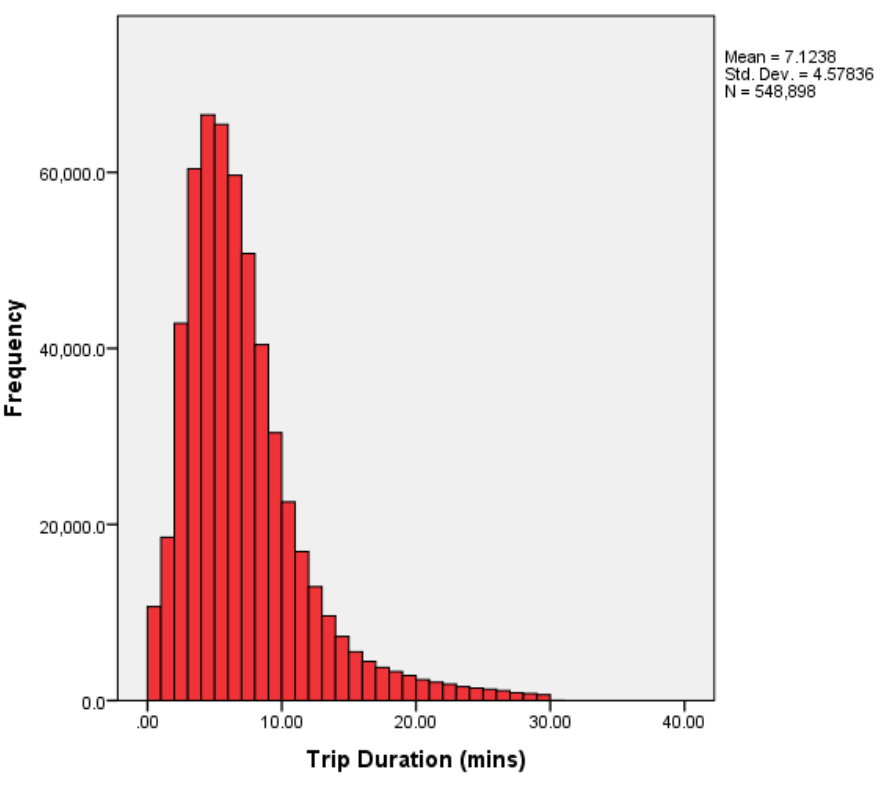

Figure 4 Trip Duration Distribution

9

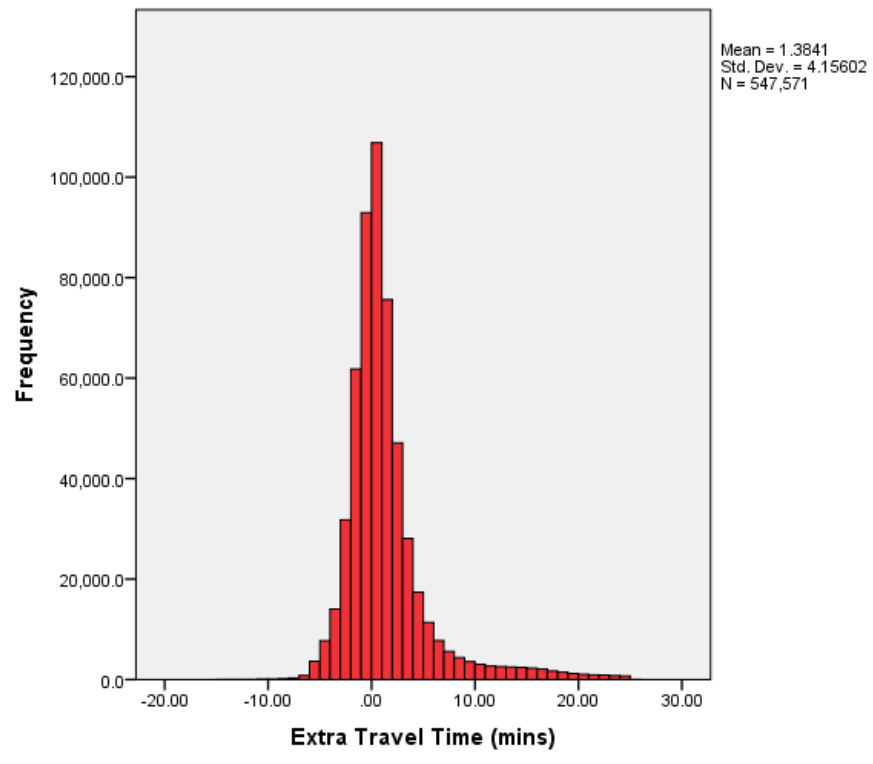

11 Figure 5 Extra Travel Time Distribution 


\section{$1 \quad$ 5.1.3 Trip Distribution by Time}

2 The usage of the public bikes also heavily depends on different temporal characteristics, with the time of

3 day being the most significant factor that influences the number of trips taken, and the day of the week and

4 month of the year also having an effect to some extent. As seen from Fig. 6 the distribution of trips

5 throughout the day follows a typical transportation time distribution with two peaks seen in both the

6 morning and evening periods. Interestingly there are also a high number of trips during the inter-peak

7 period with trips taken less frequently at the off-peak times from 9pm onwards. Fig. 7 shows for weekend

8 the traditional morning and evening peaks are gone and a more even distribution of trips occurs.

9 Fig. 8 demonstrates that there is not a significant difference in the number of trips on different weekdays 10 but at the weekend there is a considerable drop in the number of trips taken with Saturdays and Sundays 11 being the least popular day for using the bikes. Fig. 9 shows the number of trips taken each month but 12 importantly has also been segregated by the year as 2015 does not give a fair representation of the number 13 trips each month, due to the system only being implemented in December 2014 meaning that there was a 14 much lower number of trips recorded in the first few months. By examining the monthly data from 2016, it 15 is apparent that the Autumnal months from September to November have the highest frequency of trips. As 16 previously stated Cork has a large University (18,000+ students) and an Institute of Technology (12000+ 17 students), this increase in September and November may be due to the large number of students returning 18 to the city. As the dataset does not include any information on the users it is not possible to confirm this 19 assumption. 


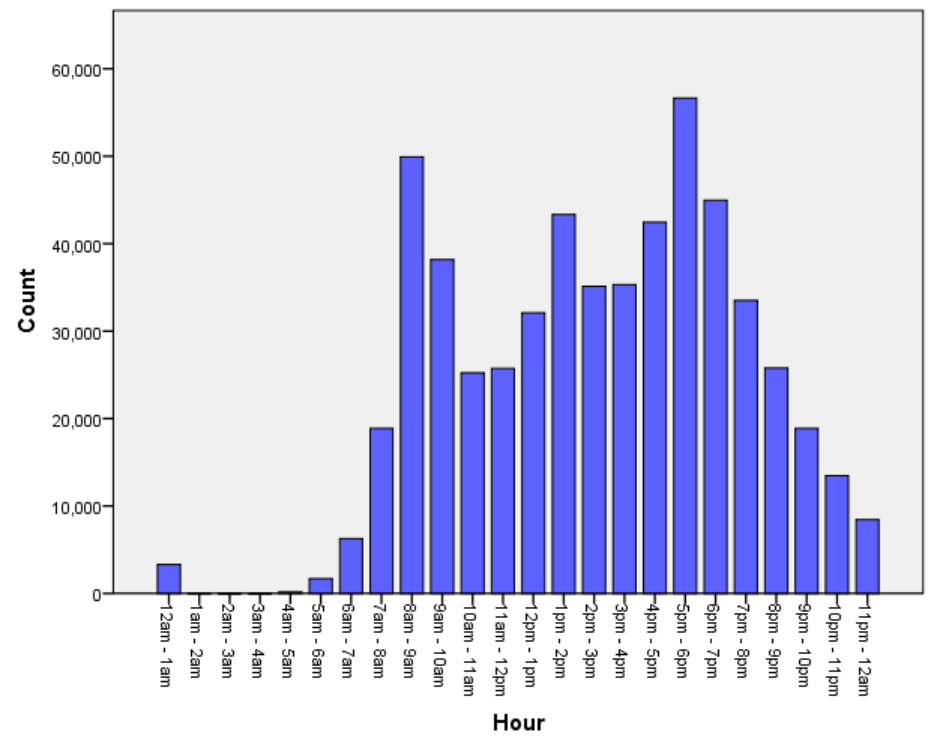

Figure 6 Trip Distribution by Hour of the Day - Weekday

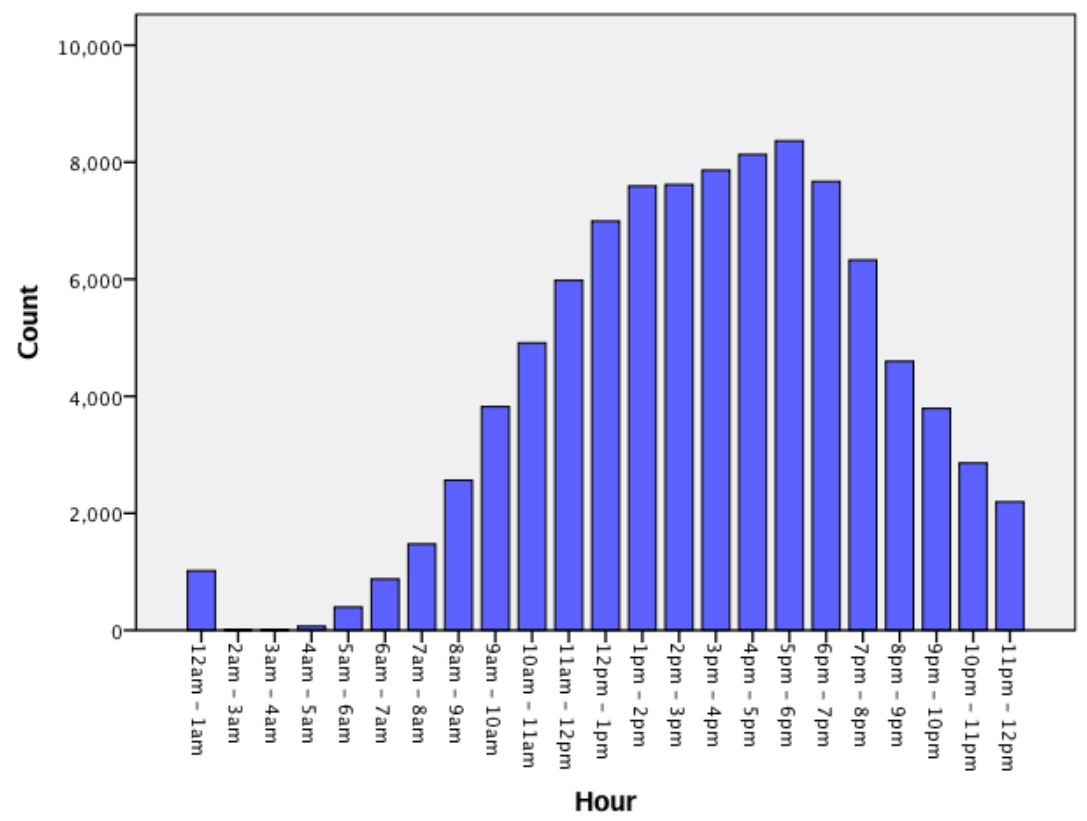

3 Figure 7 Trip Distribution by Hour of the Day - Weekend 


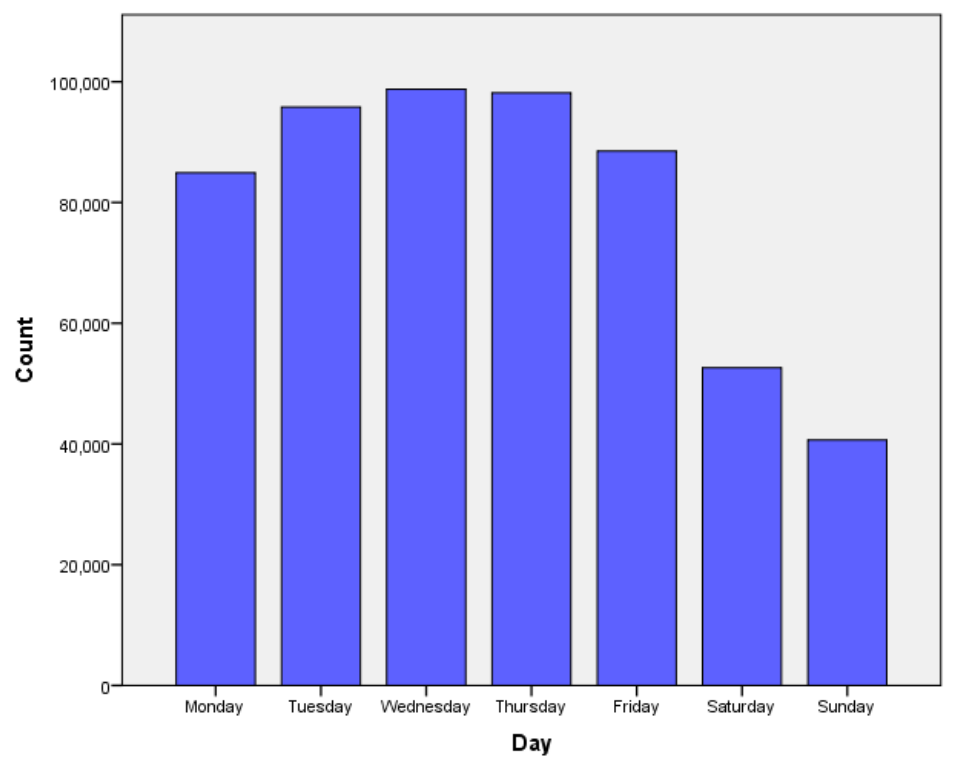

Figure 8 Trip Distribution by Day of the Week

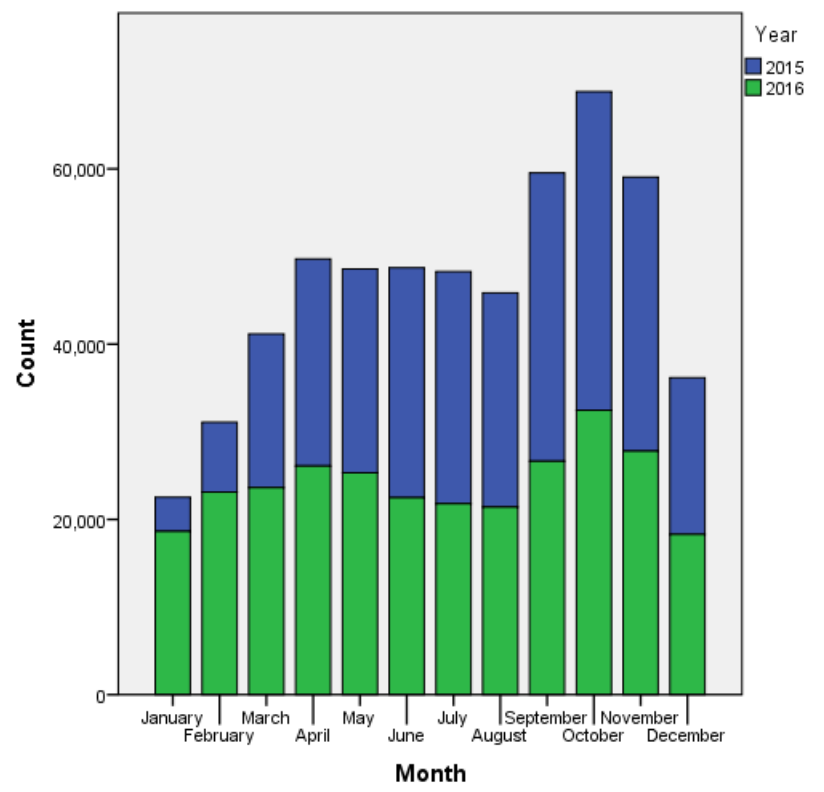

Figure 9 Trip Distribution by Month \& Year

\subsection{MNL Regression Models (Journey Time Variation as Dependent Variable)}

8 The MNL Regression model summarised in Table 4 has been developed using Journey Time Variation as

9 the dependent variable. The model has a Nagelkerke $\mathrm{R}^{2}$ value of 0.257 , suggesting that these independent 10 variables included in the model explains over one quarter of the variance of these different categories of 11 journey time variation. Although this value may seem low, it is noteworthy that the purpose of each trip is 12 not known nor the identity or demographics of each user, meaning that the spatial variables and other 13 variable types included in the model do predict the variance in journey times to a reasonable extent as each 
1 of them are deemed to be significant in the full modelling results. In this model the reference category is 2 trips that are more than 2 minutes 26 seconds slower than what Google Maps insinuates as the expected 3 journey time for the safe cycling route time between two bike stations. The other three categories that are 4 compared with this reference category are trips that are more than 47 seconds quicker than Google Maps 5 (Category 1), trips that are between 46 seconds quicker and 35 seconds slower (Category 2) and trips that 6 are between 34 seconds and 2 minutes 26 seconds slower (Category 3 ).

Table 2 MNL Regression Model

\begin{tabular}{|c|c|c|c|c|c|c|}
\hline & & $\mathbf{N}$ & $\%$ & $\begin{array}{l}\text { Trips more than } 47 \text { seconds } \\
\text { quicker than google maps }\end{array}$ & $\begin{array}{l}\text { Trips } 46-35 \text { seconds } \\
\text { slower than google maps }\end{array}$ & $\begin{array}{l}\text { Trips } 34-146 \text { seconds } \\
\text { slower than google maps }\end{array}$ \\
\hline & Intercept & & & $-1.057 * *$ & $-0.439 * *$ & $-0.071 *$ \\
\hline \multirow{2}{*}{$\begin{array}{l}\text { One- } \\
\text { Way } \\
\text { Start }\end{array}$} & No & 173472 & 31.0 & $-1.430^{* *}$ & $-0.288^{* *}$ & $-0.048 * *$ \\
\hline & Yes & 385981 & 69.0 & $0^{\mathrm{b}}$ & $0^{\mathrm{b}}$ & $0^{\mathrm{b}}$ \\
\hline \multirow{2}{*}{$\begin{array}{l}\text { One- } \\
\text { Way } \\
\text { End }\end{array}$} & No & 172282 & 30.8 & $-0.910 * *$ & $-0.321 *$ & $-0.066^{* *}$ \\
\hline & Yes & 387171 & 69.2 & $0^{\mathrm{b}}$ & $0^{\mathrm{b}}$ & $0^{\mathrm{b}}$ \\
\hline \multirow{2}{*}{$\begin{array}{l}\text { Interior/ } \\
\text { Exterior } \\
\text { Start } \\
\end{array}$} & Interior & 211332 & 37.8 & $-0.332 * *$ & $-0.352 * *$ & $-0.163 * *$ \\
\hline & Exterior & 348121 & 62.2 & $0^{\mathrm{b}}$ & $0^{\mathrm{b}}$ & $0^{\mathrm{b}}$ \\
\hline \multirow{2}{*}{$\begin{array}{l}\text { Interior/ } \\
\text { Exterior } \\
\text { End }\end{array}$} & Interior & 235594 & 42.1 & $0.248^{* *}$ & $0.119 * *$ & $-0.055^{* *}$ \\
\hline & Exterior & 323859 & 57.9 & $0^{\mathrm{b}}$ & $0^{\mathrm{b}}$ & $0^{\mathrm{b}}$ \\
\hline \multirow{2}{*}{$\begin{array}{l}\text { Cycle } \\
\text { Friendly } \\
\text { Start }\end{array}$} & No & 383914 & 68.6 & $1.365^{* *}$ & $0.238^{*}$ & $0.024^{*}$ \\
\hline & Yes & 175539 & 31.4 & $0^{\mathrm{b}}$ & $0^{\mathrm{b}}$ & $0^{\mathrm{b}}$ \\
\hline \multirow{2}{*}{$\begin{array}{l}\text { Cycle } \\
\text { Friendly } \\
\text { End }\end{array}$} & No & 395234 & 70.6 & $0.494 * *$ & $0.222 *$ & $0.127 * *$ \\
\hline & Yes & 164219 & 29.4 & $0^{\mathrm{b}}$ & $0^{\mathrm{b}}$ & $0^{\mathrm{b}}$ \\
\hline \multirow{4}{*}{$\begin{array}{l}\text { Shops } \\
\text { Start }\end{array}$} & 6 Shops or less & 276984 & 49.5 & $2.202^{* *}$ & $0.691 * *$ & 0.220 \\
\hline & 7 - 12 Shops & 72590 & 13.0 & $1.818^{*}$ & $0.851 * *$ & 0.108 \\
\hline & 13 - 31 Shops & 99798 & 17.8 & $1.295^{* *}$ & $0.504 * *$ & 0.097 \\
\hline & $\begin{array}{l}32 \text { Shops or } \\
\text { more }\end{array}$ & 110081 & 19.7 & $0^{\mathrm{b}}$ & $0^{\mathrm{b}}$ & $0^{\mathrm{b}}$ \\
\hline \multirow{4}{*}{$\begin{array}{l}\text { Shops } \\
\text { End }\end{array}$} & 6 Shops or less & 260977 & 46.6 & $0.996^{* *}$ & $0.698^{*}$ & 0.328 \\
\hline & 7 - 12 Shops & 67250 & 12.0 & $0.773^{* *}$ & $0.443 * *$ & 0.207 \\
\hline & 13 - 31 Shops & 98454 & 17.6 & $0.390 *$ & $0.170^{* *}$ & 0.139 \\
\hline & $\begin{array}{l}32 \text { Shops or } \\
\text { more }\end{array}$ & 132772 & 23.7 & $0^{\mathrm{b}}$ & $0^{\mathrm{b}}$ & $0^{\mathrm{b}}$ \\
\hline \multirow{4}{*}{$\begin{array}{l}\text { Restaur } \\
\text { ants } \\
\text { Start }\end{array}$} & $\begin{array}{l}6 \text { Restaurants } \\
\text { or less }\end{array}$ & 250900 & 44.8 & $-0.507 * *$ & $-0.232 * *$ & -0.138 \\
\hline & $\begin{array}{ll}7 \quad-\quad 16 \\
\text { Restaurants }\end{array}$ & 102036 & 18.2 & $-0.813 * *$ & $-0.482 * *$ & -0.284 \\
\hline & $\begin{array}{ll}17 \quad- & 30 \\
\text { Restaurants }\end{array}$ & 98389 & 17.6 & $-0.708^{* *}$ & $-0.047 * *$ & 0.043 \\
\hline & $\begin{array}{l}31 \text { Restaurants } \\
\text { or more }\end{array}$ & 108128 & 19.3 & $0^{\mathrm{b}}$ & $0^{\mathrm{b}}$ & $0^{\mathrm{b}}$ \\
\hline \multirow{3}{*}{$\begin{array}{l}\text { Restaur } \\
\text { ants } \\
\text { End }\end{array}$} & $\begin{array}{l}6 \text { Restaurants } \\
\text { or less }\end{array}$ & 233070 & 41.7 & $-1.261 * *$ & $-0.532 * *$ & -0.162 \\
\hline & $\begin{array}{ll}7 \quad-\quad 16 \\
\text { Restaurants }\end{array}$ & 99236 & 17.7 & $-0.670^{*}$ & $-0.464 * *$ & -0.287 \\
\hline & $\begin{array}{l}17 \quad-\quad 30 \\
\text { Restaurants }\end{array}$ & 101302 & 18.1 & $-1.008 * *$ & $-0.595^{*}$ & -0.206 \\
\hline
\end{tabular}




\begin{tabular}{|c|c|c|c|c|c|c|}
\hline & $\begin{array}{l}31 \text { Restaurants } \\
\text { or more }\end{array}$ & 125845 & 22.5 & $0^{\mathrm{b}}$ & $0^{\mathrm{b}}$ & $0^{\mathrm{b}}$ \\
\hline \multirow{2}{*}{$\begin{array}{l}\text { Public } \\
\text { Transpo } \\
\text { rt Links } \\
\text { Start }\end{array}$} & $\begin{array}{l}\text { Below } \\
\text { Average }\end{array}$ & 333049 & 59.5 & $-0.747 * *$ & $-0.225 * *$ & -0.043 \\
\hline & $\begin{array}{l}\text { Above } \\
\text { Average }\end{array}$ & 226404 & 40.5 & $0^{\mathrm{b}}$ & $0^{\mathrm{b}}$ & $0^{\mathrm{b}}$ \\
\hline \multirow{2}{*}{$\begin{array}{l}\text { Public } \\
\text { Transpo } \\
\text { rt Links } \\
\text { End }\end{array}$} & $\begin{array}{l}\text { Below } \\
\text { Average }\end{array}$ & 328226 & 58.7 & $-0.373 * *$ & $-0.100^{* *}$ & 0.083 \\
\hline & $\begin{array}{l}\text { Above } \\
\text { Average }\end{array}$ & 231227 & 41.3 & $0^{\mathrm{b}}$ & $0^{\mathrm{b}}$ & $0^{\mathrm{b}}$ \\
\hline \multirow{4}{*}{$\begin{array}{l}\text { Distanc } \\
\mathrm{e}\end{array}$} & $718 \mathrm{~m}$ or less & 84730 & 15.1 & $1.013 * *$ & $1.493 *$ & 0.709 \\
\hline & $719-1087 \mathrm{~m}$ & 118428 & 21.2 & $1.242 *$ & $1.302 * *$ & 0.814 \\
\hline & $1088-1596 \mathrm{~m}$ & 149259 & 26.7 & $0.548 * *$ & $0.872 * *$ & 0.571 \\
\hline & $\begin{array}{lll}\begin{array}{l}1597 \\
\text { more }\end{array} & \mathrm{m} & \text { or } \\
\end{array}$ & 207036 & 37.0 & $0^{\mathrm{b}}$ & $0^{\mathrm{b}}$ & $0^{\mathrm{b}}$ \\
\hline \multirow{4}{*}{$\begin{array}{l}\text { Total } \\
\text { Origin- } \\
\text { Destinat } \\
\text { ion Pair } \\
\text { Trips }\end{array}$} & $0-500$ & 130698 & 23.4 & $-0.517 * *$ & $-0.469 * *$ & -0.476 \\
\hline & $501-1000$ & 129145 & 23.1 & $-0.340 * *$ & $-0.298 * *$ & -0.449 \\
\hline & $1001-2000$ & 159745 & 28.6 & $-0.042 *$ & $-0.178^{*}$ & -0.293 \\
\hline & Over 2000 & 139865 & 25.0 & $0^{\mathrm{b}}$ & $0^{\mathrm{b}}$ & $0^{\mathrm{b}}$ \\
\hline \multirow{4}{*}{$\begin{array}{l}\text { Total } \\
\text { User } \\
\text { Trips }\end{array}$} & 7 Trips or less & 7334 & 1.3 & $-2.374 * *$ & $-1.710^{* *}$ & -1.059 \\
\hline & $8-26$ Trips & 31721 & 5.7 & $-1.392 * *$ & $-0.973 * *$ & -0.571 \\
\hline & $27-81$ Trips & 104679 & 18.7 & $-0.799 * *$ & $-0.548 * *$ & -0.289 \\
\hline & $\begin{array}{l}82 \text { Trips or } \\
\text { more }\end{array}$ & 415719 & 74.3 & $0^{\mathrm{b}}$ & $0^{\mathrm{b}}$ & $0^{\mathrm{b}}$ \\
\hline \multicolumn{6}{|l|}{$\mathrm{N}$} & 559,453 \\
\hline \multicolumn{6}{|c|}{-2 log likelihood at convergence } & 213319.603 \\
\hline \multicolumn{6}{|c|}{ Log Likelihood ratio test } & 2.660 \\
\hline \multicolumn{6}{|c|}{ Nagelkerke $\mathrm{R}^{2}$} & 0.257 \\
\hline \multicolumn{6}{|c|}{ Chi-squared statistic } & 154209.6 \\
\hline \multicolumn{6}{|c|}{ Degrees of Freedom } & 87 \\
\hline
\end{tabular}

1 a. The reference category is: More than 2 minutes 26 seconds slower.

2 b. Reference terms

$3 \quad *$. This has a significance $p$-value $>0.01$.

$4 \quad * *$. This has a significance $p$-value $>0.05$

From examining Table 6 in closer detail, each individual independent variable can be inspected and evaluated for their contribution in predicting the journey time variation among the trips. One-Way starts and ends to each trip were associated with the quicker trips indicating that cyclists may be more conservative with their cycling speeds when there is two-directional traffic. To a lesser extent trips that commenced at one of the exterior stations, and trips that ceased at interior stations were also linked with the

11 more direct, quicker trips. Remarkably stations that were on roads considered to be "Cycle Friendly" by

12 Google Maps were related to slower trips which may contradict the evidence from the existing literature.

13 However the argument could be proposed that "Cycle Friendly" streets are travelled at slower speeds 14 because there isn't the pressure on cyclists on public bikes to sustain cycling speeds similar to adjacent 15 traffic. There may be other explanations for this result, but as the database does not have a track on the 16 route on which the cyclist takes. 
Trips to and from stations that had a lower number of shops within walking distance were also found to be likely predictors of the trips with lowest extra travel time, however the converse is apparent for the number of restaurants within walking distance of stations. The number of shops at the origin station has a larger influence on the quickness of trips than the number of shops at destination stations, while the number of restaurants at destination stations had a higher influence. The stations with above average public transport links also are associated with quicker trips suggesting that users of public bikes will take quick, direct journeys if they are trip-chaining with other transportation modes such as bus or rail.

The three non-spatial variables that are included in this model are also excellent predictors of journey time variation of trips in the Cork system. The frequency of the origin-destination pair is also linked to slower trips, and this may be due to the lack of available bike stands at the destination station or possibly a high passenger footfall around the stations during busy periods. Also as expected the most frequent users of the public bikes are efficient with their cycling speeds as they are the user types that are making the trips with lowest extra travel time, while users who have taken 7 trips or less over the two-year period are much more likely to be in the slowest category of trips.

\section{Conclusion}

17 As seen from the MNL Regression modelling results, the variation in the journey times of different trips 18 depends on a number of different spatial variables, such as whether the origin and destination bike stations 19 are on one-way streets, are deemed to be "Cycle Friendly" or are an interior or exterior station in Cork city.

20 The number of shops, restaurants and public transport links also influence journey time variation, and each 21 of these variables can be examined for their strength as predictors in the results tables.

22 The Journey Time Variation variable is based on predicted journey times from the Google Maps journey planner, and these predicted journey times have proven to be similar to those journey times experienced on actual trips on the Cork public bikes. It would be interesting to see this journey planning tool being used in further research in order to assess its accuracy when measuring against actual trip journey times, but based on this research alone the journey times that were recorded from Google are precise in their predictions.

There are a number of recommendations that can be made for future work on this topic. As previously mentioned there could be more investigation into the comparisons of actual recorded trip journey times from public bike systems, but in relation to the theme of journey time variation in public bike systems there is a significant amount of more research that could be done in this area. As this research has been purely statistical analysis of the trip database in Cork, only $25.7 \%$ of the variance in the data could be explained by the spatial variables. However, a survey could be administered to the annual subscribers of the scheme in 
order to categorise the different trip purposes and other things such as age, gender, etc. to see if these factors could also explain the variation in different journey times. Another idea for future research would be the use of GPS to track different users on the public bikes which would provide a great deal of detail and understanding to the underlying aspects of journey time variation that have not been considered here.

\section{Acknowledgements}

The authors would like to thank the National Transport Authority for providing the data for this study.

\section{References}

Broach, J., J. Dill, and J. Gliebe, Where do cyclists ride? A route choice model developed with revealed preference GPS data. Transportation Research Part A: Policy and Practice, 2012. 46(10): p. 1730-1740.

Caulfield, B., Leahy, J., Learning to cycle again: examining the benefits of providing tax-free loans to purchase new bicycles, Research in Transportation Business \& Management, 2, 2011, p42 - 47

Caulfield, B., O'Mahony, M., Brazil, W., Weldon, P. , Examining usage patterns of a bike-sharing scheme in a medium sized city, Transportation Research Part A: Policy and Practice, 100, 2017, p152 - 161

Caulfield, B. Re-cycling a city - examining the growth of cycling in Dublin, Transportation Research Part A: Policy and Practice, 61, 2014, p216-226

Corcoran, J., Li, T., Rohde, D., Charles-Edwards, E., Mateo-Babiano, D. Spatio-temporal patterns of a Public Bicycle Sharing Program: the effect of weather and calendar events. Journal of Transport Geography, 2014. 41: p. 292-305

CSO. Census of Population 2016 - Profile 3 An Age Profile of Ireland, CSO, 2017

Department of Transport, Smarter Travel - A New Transport Policy for Ireland. 2009a, DoT: Dublin Department of Transport, Ireland's First National Cycling Policy Framework. 2009b, DoT: Dublin

Faghih-Imani, A. and Eluru, N. Determining the role of bicycle sharing system infrastructure installation decision on usage: Case study of montreal BIXI system. Transportation Research Part A: Policy and Practice, 2016. 94: p. 685-698

Faghih-Imani, A. and Eluru, N. How land-use and urban form impact bicycle flows: evidence from the bicycle-sharing system (BIXI) in Montreal. Journal of Transport Geography, 2014. 41: p. 306-314

Faghih-Imani, A. and Eluru, N. Incorporating the impact of spatio-temporal interactions on bicycle sharing system demand: A case study of New York CitiBike system. Journal of Transport Geography, 2016. 54: p. $218-227$ 
Fuller, D.m Sahlqvist, S., Cummins, S.m Ogilvie, D. The impact of public transportation strikes on use of a bicycle share program in London: Interrupted time series design. Preventive Medicine, 2012. 54(1): p. 7476

Google Developers. Google Maps Distance Matrix API | Google Developers. 2016 [cited 2016 24th November 2016]; Available from: https://developers.google.com/maps/documentation/distance-matrix/.

Hood, J., E. Sall, and B. Charlton, A GPS-based bicycle route choice model for San Francisco, California. Transportation letters, 2011.3(1): p. 63-75.

IBM Knowledge Center. Pseudo R-Squared Measures. 2017 [cited 2017 6th April]; Available from: https://www.ibm.com/support/knowledgecenter/SSLVMB_24.0.0/spss/tutorials/plum_germer_rsquare.html

Mateo-Babiano, I., Bean, R., Corcoran. J., Pojani, D. How does our natural and built environment affect the use of bicycle sharing? Transportation Research Part A: Policy and Practice, 2016. 94: p. 295-307

Médard de Chardon, C. and G. Caruso, Estimating bike-share trips using station level data. Transportation Research Part B: Methodological, 2015. 78: p. 260-279

Met Éireann. Download Historical Climate Data - Met Éireann - The Irish Meteorological Service Online. 2017 [cited 2017 15th February]; Available from: http://www.met.ie/climate-request/

National Transport Authority. Cork - Coca-Cola Zero® Bikes. 2017 [cited 2017 5th April]; Available from: https://www.bikeshare.ie/cork.html

O’Brien, O., J. Cheshire, and M. Batty, Mining bicycle sharing data for generating insights into sustainable transport systems. Journal of Transport Geography, 2014. 34: p. 262-273 Oliveira, G. N., Sotomayor, J.L., Torchelsen, R.P., Silva, C.T., Comba, J.L.D. Visual analysis of bikesharing systems. Computers \& Graphics, 2016. 60: p. 119-129

Romanillos, G., Zaltz Austwick, M., Ettema, D., De Kruijf, J. Big Data and Cycling. Transport Reviews, 2016. 36(1): p. 114-133

Statistics Solutions. Conduct and Interpret a Multinomial Logistic Regression - Statistics Solutions. 2017 [cited 2017 6th April]; Available from: http://www.statisticssolutions.com/mlr/

Tran, T.D., N. Ovtracht, and B.F. d'Arcier, Modeling Bike Sharing System using Built Environment Factors. Procedia CIRP, 2015. 30: p. 293-298.

Wang, X., Lindsey, G., Schoner, J.E., Harrison, A. Modeling Bike Share Station Activity: Effects of Nearby Businesses and Jobs on Trips to and from Stations. Journal of Urban Planning and Development, 2016. 142(1): p. 9

Wergin, J. and R. Buehler. Where do Bikeshare Bikes Actually Go? An Analysis of Capital Bikeshare Trips 
1 Using GPS Data. Transportation Research Record (forthcoming)

2 Zhao, J., Deng, W., Song, Y. Song, Ridership and effectiveness of bikesharing: The effects of urban 3 features and system characteristics on daily use and turnover rate of public bikes in China. Transport 4 Policy, 2014. 35: p. 253-264 